\title{
The inner patient
}

The dreaded hum of the pager on your thigh,

Shakes your self-belief with each nonchalant nudge...

You take a deep breath,

Put on a brave face and stride to the phone.

The crack in your voice threatens to betray your true emotion,

But you suppress its confession with a cough.

They're all buying it...

"Not to worry, the doctor is here now."

You stand there imagining,

What would this patient think if he knew,

That you were the main audience for your own reassurances?

"I know this is difficult but you'll get through this...

There are people here to help you-you're not alone...

It'll all be okay; you just need to relax until the morning..."

"Easier said than done!"

A voice replies.

You keep trying but can't get through to him.

No amount of self-prescribed logic seems to help.

He's resistant, non-compliant and ?unstable.

I suppose doctors really do make the worst patients.

Usama Mohammad Syed, ${ }^{1}$ Shirin Ahmed ${ }^{2}$

${ }^{1}$ Faculty of Medicine, Imperial College London, London, UK

${ }^{2}$ Faculty of Medicine, King's College London, London, UK

Correspondence to Usama Mohammad Syed, Flat D4, Kenilworth Court, Hagley Road, Birmingham, B16 9NU, UK; us910@imperial.ac.uk, us910@ic.ac.uk

Contributorship Statement The idea for this piece of poetry was formulated by UMS initially under the title of 'Bump in the Night'. Having received feedback from the editors UMS approached SA to ask for help and a fresh perspective and to conceptualise my new slant on the piece. Together UMS and SA reformatted the poem as 'The Inner Patient'. Joint discussion was held and wording refined.

Competing interests None.

Provenance and peer review Not commissioned; internally peer reviewed.

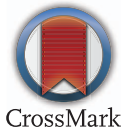

To cite Syed UM, Ahmed S. Med Humanit 2015;41:e8.

Med Humanit 2015;41:e8. doi:10.1136/medhum-2015-010668 